Kansas State University Libraries

New Prairie Press

\title{
APPLICATION OF COMPUTER INTENSIVE METHODS TO EVALUATE THE PERFORMANCE OF A SAMPLING DESIGN FOR USE IN COTTON INSECT PEST MANAGEMENT
}

\author{
J. L. Willers \\ W. L. Ladner \\ J. M. McKinion \\ W. H. Cooke
}

See next page for additional authors

Follow this and additional works at: https://newprairiepress.org/agstatconference

Part of the Agriculture Commons, and the Applied Statistics Commons c) (i) $\odot$

This work is licensed under a Creative Commons Attribution-Noncommercial-No Derivative Works 4.0 License.

\section{Recommended Citation}

Willers, J. L.; Ladner, W. L.; McKinion, J. M.; and Cooke, W. H. (2000). "APPLICATION OF COMPUTER INTENSIVE METHODS TO EVALUATE THE PERFORMANCE OF A SAMPLING DESIGN FOR USE IN COTTON INSECT PEST MANAGEMENT," Conference on Applied Statistics in Agriculture. https://doi.org/10.4148/ 2475-7772.1245

This is brought to you for free and open access by the Conferences at New Prairie Press. It has been accepted for inclusion in Conference on Applied Statistics in Agriculture by an authorized administrator of New Prairie Press. For more information, please contact cads@k-state.edu. 


\section{Author Information}

J. L. Willers, W. L. Ladner, J. M. McKinion, and W. H. Cooke

This is available at New Prairie Press: https://newprairiepress.org/agstatconference/2000/proceedings/11 


\title{
APPLICATION OF COMPUTER INTENSIVE METHODS TO EVALUATE THE PERFORMANCE OF A SAMPLING DESIGN FOR USE IN COTTON INSECT PEST MANAGEMENT
}

\author{
J. L. Willers, W. L. Ladner, and J. M. McKinion \\ Genetics and Precision Agriculture Research Unit, Mississippi State, MS \\ and \\ W. H. Cooke \\ USDA Forest Service, Forestry Sciences Laboratory, Mississippi State, MS
}

\begin{abstract}
A scouting protocol for cotton insect pests was developed which combines high resolution, multispectral remotely sensed imagery with a belt transect that crosses rows of cotton. Imagery was used to determine sample site selection while estimating plant bug abundance in a more than 200 ac. cotton field in 1997. Tarnished plant bug (Lygus lineolaris) counts were acquired using a standard drop cloth for each of eight rows along a transect. The sample data indicated that plant bug population densities spatially vary as a function of different spectral (color) classes present on the imagery. We postulate that such classified images correlate to differences in crop phenology, and plant bug populations (especially from early to mid-season) aggregate themselves by these habitat differences. Therefore, the population dynamics of Lygus, and possibly other species, can be better understood by combining the transect-based sampling plan with remotely sensed imagery. To verify and validate this claim, a computer intensive approach was utilized to simulate the performance of different sampling plans. The comparison is accomplished with a combinatorial algorithm that exhaustively enumerates the original data into unique subsets. These subsets correspond to results that could be expected from the use of traditional or alternative sampling plans and compared to results from the candidate plan actually used. The results of the enumerative analysis show the benefit of multi-band, remotely sensed imagery combined with the use of large sized sample units to improve sampling efficiency (and without the need to have large sample sizes). It is of great benefit that the enumerative algorithm provided answers to questions of interest without having to complete additional fieldwork.
\end{abstract}

Key Words: Sampling, enumeration, integrated pest management, remote sensing, precision agriculture.

\section{Introduction}

Arthropod pests of agricultural crops are one of several causes for yield loss. For example, total yearly losses to cotton in 1997 for the United States are estimated to be $9.42 \%$. However, this percentage, when converted to dollars, represents a loss to production of more than $\$ 785$ million 
(Williams, 1998; 2000). When the cost of control (i.e., money spent to prevent loss) is considered, the combined US total is estimated at more than 1.4 billion dollars (Williams, 1998). Significant dollars are spent just in collecting the data used to make management decisions to control insects and mites in cotton. Cotton insect monitoring costs across the US cotton belt average $\$ 6.52 /$ scouted acre, for an estimated total of about 57 million dollars.

The potential exists to improve the management of arthropod pests at lower cost and improve yield. Some of the key hemipterous pests (King et al., 1996) across the Cotton Belt are the plant bugs (Lygus lineolaris (P. de B.)), L. hesperus Knight, and the cotton fleahopper (Pseudatomoscelis seriatus (Reuter)). The sampling literature for hemipterous pests is quite large, numbering more than 41 references if crops other than cotton are considered (Willers and Akins, 2000). The key for improved management is to better understand the population dynamics of these pests and important beneficial insects and spiders. Obtaining good estimates of the spatial and temporal trends of both the pest and beneficial insects is necessary. Knowledge of how abiotic factors influence these trends is also essential. Today, much is known, but losses in yield still occur. Therefore gaps remain in our understanding, both for measuring population abundance and learning how the different biological components fit together (Pedigo and Buntin, 1993).

Previously, Ludwig and Reynolds (1988) discussed how the size (i.e., scale) of the sample unit influences the assessment of spatial pattern for arbitrarily defined sample units. In this paper, we illustrate how sample unit size and the presence or absence of stratification influence estimates of population density for a fixed sample number size $(n=4)$. It will be argued that sample unit size has a tremendous impact upon the precision of population estimates. Consideration of this effect of sample unit size (i.e., how big of a unit is searched for insects) is as important as sample number (i.e., how many units were searched). The two influences work together, and when accounted for in a sample scheme that also employs stratification (as established by multi-spectral imagery), dependable estimates of plant bug abundance in cotton can be obtained with less effort and smaller sample sizes.

Other entomologists need to be shown the benefit of these concepts. Therefore, we developed an exhaustive enumerative algorithm that could 'resample' a data set acquired through the use of imagery, large sized sample units, and use 'small' sample sizes. By setting different constraints, the algorithm generated various other sampling plans including one that mimics the performance of traditional sampling efforts employed by cotton entomologists (Table 1). The algorithm therefore demonstrated the benefit of stratification (by remotely sensed imagery) and assessed impacts of different sample unit sizes while holding the sample number size constant ( $n=$ 4). Demonstrating reliable estimates with small sample sizes is important, since entomologists desire to save time while scouting large numbers of fields each week. The sample data described in this article pertain to selected results from the 1997 crop year (Willers et al., 1999). These data were obtained while sampling cotton for the pest, Lygus lineolaris (or the Tarnished Plant Bug (TPB)).

\section{Methodology}

The foundation for the improved sampling scheme is based upon the classical line-intercept 
sampling (LIS) design described by Kaiser (1983), Lucas and Seber (1977), McDonald (1980; 1991), and Thompson (1992). Willers et al. (1992) and Willers and Akins (2000) describe in detail the adaption of LIS concepts to row crop applications. General notes of interest on this modified LIS (MLIS) technique are found in Willers (1998). Additional concepts relevant to the use of MLIS for cotton insect sampling and for the results of this study are described in Pielou (1977), Thompson (1992), and Willers et al. (1990a,b; 1992).

\section{a. Sampling Procedure (MLIS)}

Transect lines up to eight (crop) rows in length are established perpendicular to the row direction in commercial cotton fields. The number of plant bugs discovered on a drop cloth (after insects are dislodged onto the cloth by vigorous shaking of plants) are counted for every row. The points of beginning (i.e., origin) for these transect lines are placed within areas of the field where the crop is judged to be homogenous for such characteristics as growth rate, height, canopy development, and fruit load. Establishing the boundaries and/or extent of these homogenous areas (i.e., strata) is accomplished using multi-spectral, remote sensing imagery (Schrader and Pouncy, 1997; Willers et al., 1999). Thus, the use of high-resolution, multi-spectral imagery is an integral part of the MLIS sample design.

\section{b. Classical LIS estimator and modification for MLIS}

The classical LIS estimator (Kaiser (1983), Lucas and Seber (1977), McDonald (1980; 1991)) is now briefly described. To estimate the attribute totals, $\hat{Y}$ (i.e., the No. TPB per acre), for all $y$ in $A$, a simple equation can be used. Sample data $\left(y_{i}\right)$ collected from the $i$-th quadrat along a transect line of known length is substituted into the following equation:

$$
\hat{Y}=W \sum_{i=1}^{n}\left(y_{i} / l_{i}\right)=W / l \sum_{i=1}^{n}\left(y_{i}\right)
$$

where $l$ is the drop cloth width and $W$ is a reference baseline of known length used to scale the sample data to unit area $(A)$.

Through the use of algebra, eqn. (1) can be manipulated into a form that reflects the row crop environment. This form is a simple expression (eqn. 2; Willers et al., 1999) that readily estimates the number $(\hat{Y})$ of plant bugs per acre (or 0.405 ha). Here, the total number of bugs (either the number of teneral adults or nymphs, respectively, or the combined count of teneral adults and nymphs) observed from the transect is divided by the total number row feet (or meters) sampled (i.e., the drop cloth length ( $l$, the side that lies parallel to the rows) multiplied by number of rows $(n)$ sampled along a line). The quotient is multiplied by the linear row feet per acre $(R)$ (or number of 
linear meters per 0.405 ha) applicable to the reference area, $A$, as shown in eqn. 2. Both forms (eqns. 1 and 2) are useful in the analysis of results typical of those described in this study.

$$
\hat{Y}=\left[\sum_{i=1}^{n} y_{i} /(n * l)\right] * R
$$

\section{c. Image acquisition and processing}

Specific details about the acquisition of remotely sensed imagery by aircraft and color examples of images (after computer enhancement) of cotton fields are found in Seal (1999) and Willers et al. (1999). We summarize the computer processing of these images into a format that was useful for selection of stratified sample sites within a field of cotton (ca. 200 acres in sizes). The images used in this study required band-to-band registration. Each band was acquired by a separate camera positioned at a slightly different look angle in the aircraft bay which results in band-to-band mis-registration. Control points common to each band were chosen to facilitate warping of each band to the near infrared (NIR) band. Although the green band showed road intersections a bit more clearly than the NIR band, the longer wavelengths of the NIR band provided the most spatially accurate standard for band-to-band warping procedures. Whenever possible, right angle road intersections were used for control points. In cases where road intersections were not available, other less desirable control points were used. A first order polynomial equation (McCloy, 1995) was used to fit the image data to the control image (i.e., NIR band). The pixels in bands other than the NIR band were changed in their position and orientation and it was necessary to resample these bands. Nearest neighbor resampling (Lillesand and Kiefer, 1987) was used to assign radiometric values to the slightly altered (spatially) pixels in the output images. Nearest neighbor resampling assigns the radiometric value of the closest pixel in the input matrix (original image) to the output image disregarding the slight offset. This method is computationally simple and avoids altering original input pixel values (Lillesand and Kiefer, 1987). A target minimum of 12 control points was used for 'warping' each band to the near infrared (NIR) band. These points were distributed as evenly as possible across each image. Once each band was rectified to the NIR band, all bands were combined in a single co-registered multi-band image. This final image was used to select sample points in the cotton field.

\section{d. Exhaustive enumeration algorithm for generation of competing sample designs}

Development of the analysis technique used to compare performance of competing sampling designs is based on an algorithm written in the $\boldsymbol{C}$ programming language (Kernighan and Ritchie, 1988) that accomplished the task of exhaustive enumeration (Manly, 1997). There are 'canned routines' (e.g., Press et al., 1989) available that can perform most of the necessary tasks. However, it was necessary to generate combinations from several matrices of different ranks derived from original MLIS variates. Therefore, several customized $\boldsymbol{C}$ subroutines were programmed to create 
an enumerative algorithm that varied the extent of stratification, sample unit size, and sample size to simulate the performance of different sample designs (Table 1).

The original MLIS sample data can be arranged in a table (e.g., see Tables $1 \mathrm{~A}$ and $1 \mathrm{~B}$ in Willers et al., 1999) and considered to be a matrix of $r$ rows and $c$ columns. The algorithm operated on these matrices. Each row in a matrix corresponded to a MLIS transect and each column corresponded to a crop row along the length of the belt transect. Thus, for the $r$-th, 8 -row long transect line sample $\left(l_{r}\right)$, it is possible to create seven unique sets of adjacent crop row pairs as follows (each number in a pair corresponds to a crop row along the transect line): $\{(1,2)$ or $(2,1)\}$, $\{(2,3)$ or $(3,2)\},\{(3,4)$ or $(4,3)\},\{(4,5)$ or $(5,4)\},\{(5,6)$ or $(6,5)\},\{(6,7)$ or $(7,6)\}$, and the seventh set of $\{(7,8)$ or $(8,7)\}$. These seven arrangements constitute the fundamental building blocks that enabled the generation of different sample unit sizes. Any pair in a row was the smallest sample unit size used in this study. The sample number was fixed at four $(n=4)$ in all instances, because by tradition only four samples for plant bugs are collected by field scouts in any given cotton field.

The results from the enumerative method can be considered exact in that every possible allocation or number of combinations of $r$ distinct items taken $c \leq 7$ at a time (Beyer, 1968; Manly, 1997) as described by:

$$
\left(\begin{array}{l}
r \\
c
\end{array}\right)=C(r, c)=\frac{r !}{c !(r-c) !}
$$

Combinations (rather than permutations) are of interest in this research, because once a particular arrangement (or set) of ' $r$ choose $c$ ' has occurred, other possible orderings of the items in that particular set are of no interest. Therefore, the task of listing all sets from a matrix of MLIS sample data for different values of $r \leq 4$ ( where $r_{i} \neq r_{j}$ ) and $c$ can be time consuming due to the fact that sets of combinations are never to be duplicated (i.e., permutations), yet all possible combinations $(N)$ must be found. The $\boldsymbol{C}$ subroutines found all unique sample combinations from a data matrix in which the number of rows $(r)$ exceeded the sample size $(n)$, and met the restriction that once a row in the matrix was 'sampled' it was not permissible to enter that row again for the $i$-th simulated sample or until $(i=n)<r$. An equation describing how these various constraints modify eqn. 3 is:

$$
N=\frac{\prod_{j=0}^{n-1}(r-j)(c)}{n !}
$$

The denominator of eqn. 4 removes permutations that are from repetitive combinations generated by the subroutine that implements the logic of the numerator. This equation serves as check to compare if the total frequency counts shown in the bottom of Table 2 are correct results for the particular matrix used to simulate a sample plan (Table 1, the last column).

Articles similar to Hayes (1996) or Copeland and Haemer (1999), texts by Manly (1997) or Sloane and Plouffe (1995) and websites (e.g., Sloane, 1999) were resources that provided many concepts employed in building the subroutines. 


\section{Results}

Since the original MLIS data was based on transects placed in different strata determined by imagery, we easily created unstratified or stratified samples to show the benefit of imagery. The impact of stratified samples for different sample unit sizes could also be readily studied by 'resampling through enumeration' the original data found in Willers et al. (1999). Comparisons among the performance of competing sampling designs using exhaustive enumeration are presented in Table 2 and illustrated in Figs. 1 - 2. One key feature of these results is that the total number of combinations varies according to the size of the data matrix used for the resampling (i.e., exhaustive enumeration). The number of draws ranges from a maximum of 25,513,026 for a $24 \times 7$ array (Table 1, Unstratified) down to 36,015 (Table 1, Stratified) for a $6 \times 7$ array. If the sample unit size increases, the array size can be as small as a $6 \times 1$ (the four strata with the full 8-row sample line), or only 15 combinations.

The frequencies for the different estimates of population means (Table 2) provide a clear summarization of an enumerative analysis that both generates and compares probable results from the different sampling plans. For example, a field scout using the unstratified plan (with a sample unit size of 6 linear $f t$ and a sample size of 4$)$ would be expected to conclude $(5,275,184 / 25,513,023)$ $\mathrm{x} 100=20.7 \%$ of the time that there were no TPB in the field. This is the conclusion that could be expected if this traditional sampling plan had been employed in this field with its population density and dispersion pattern as found by MLIS during July, 1999 (Willers et al., 1999). This a considerable error, especially when the stratified plan of the same configuration (Table 2) shows that two of the four habitat classes are probably infested with TPB at a high rate (i.e., the Best and Good habitats). If we examine the estimated distribution for the Best habitat using the traditional sample unit size (i.e., 6 linear $f t$; Table 2) it is seen that one would conclude $0.82 \%$ of the time that the TPB density was zero $((295 / 36,015) \times 100)$. By comparison, the MLIS sample design with a larger sample unit size (i.e., 24 linear $f t$ ) but the same sample size, would be expected to conclude (Fig. 2) that the population density for the Best habitat during July, 1999 was $>1,290$ TPB per acre onehundred percent of the time (i.e., ( 9 or more TPB $\div(24$ linear $f t$ per sample $\times 4$ samples $)$ ) x 13, 756 linear $f t$ per acre $\times 15 / 15)$. Clear elimination of the zero alternative, when combined with entomological expertise, affords tremendous clarity when also associated with spatial information. Clearly, parts of the field have a TPB problem while other portions do not. Other questions of interest can be easily addressed in a similar fashion. For example, should one continue to use a sample size of four in the Fair or Poor habitat groups? Or, should one pool the two favorable habitats (Best and Good) into a single group and sample those regions of the field only twice instead of four (or eight) times. Therefore, the enumerative results can be combined with the expertise of a field consultant to alter traditional entomological sampling practices.

The enumerative results also show the lack of a symmetrical distribution (Table 2) for some sample plans (e.g., Unstratified) or as a result of the naturally occurring population abundance within a particular habitat (e.g., the Fair or Poor habitats). The density class having the highest frequency of occurrence is the mode. It should be noted that the mode of each stratified distribution (using the Best habitat as a point of comparison) across the various sample unit sizes scales to equivalent density estimates (i.e., 1,720 insects per acre (Table 2); 1, 433 insects per acre ( Fig. 1); and 1,862 
insect per acre (Fig. 2). The slight differences are of no consequence in the making of pest management decisions.

The enumeration analysis indicates that MLIS with a large sample unit size created by use of drop cloth improves sample precision. Use of imagery to define distinct strata corresponding to different states of crop growth also improves sampling precision. Comparisons of results involving three sample unit sizes (i.e., paired rows, four adjacent rows, and eight adjacent rows) while holding fixed the sample number size $(n=4)$ readily shows how low population densities can be separated from high population densities (Table 2 and Figs. 1 and 2). This small sample size used in this study corresponds to a common rule of thumb employed by consultants in order to save time. If field scouts want to continue to use small sample sizes to save time, then these results indicate that they should use larger sized sample units. If the sample size and sample unit size are both too small then large errors in correctly estimating the population density will frequently occur.

\section{Discussion}

Ecologists, including those who study insect populations, have known for some time that both the identification of spatial pattern and density are heavily influenced by the size of the sample unit. Detecting whether a population is clumped or randomly dispersed is strongly determined by the sample unit size (Ludwig and Reynolds, 1988; Wilson and Room, 1983). In this light, it is of interest that MLIS uses quadrats strongly tied to units of area (i.e., cells along the belt transect) rather than the plant itself or small collections of plants along a row. Traditionally, many entomological sampling designs (Pedigo and Buntin, 1993) emphasize the use of plants as the entities that define the sampling unit size. For MLIS, plants are merely the substrate within each quadrat (or cell) along a transect line on which TPB reside. This is an important but subtle distinction that should be kept in mind.

Often, with low populations, a transect line that is too short will bias upwards the estimate of numbers per acre. By making a simultaneous appeal with the results described here with earlier results reported for the simulation study by Willers et. al. (1990a), the bias that occurs with shorter transects at low population densities (McDonald, 1991) can be explained. For example, as the sample unit size becomes smaller and approaches the size of a single plant, the chance that any randomly drawn sample unit will be found with an insect (of a particular kind or life stage) decreases as the abundance of that insect decreases, but the efficiency (i.e., success of discovery) of examining a sample unit increases as its size becomes smaller. Conversely, as the sample unit increases in size, the chance that an insect occurs somewhere inside the sample unit increases (Willers et al., 1990a), but at the penalty of spending more time and effort examining the sample unit. Thus, an important consideration of any sampling scheme is the relationship of the size of the sample unit to the ease with which insects are detected. The drop cloth used with MLIS allows the sampling of large sized sample units in a short time.

When the sampling distribution describing the variability in population abundance is asymmetrical (i.e, non-normal) the mode is not equivalent to the mean. Results obtained here document one finding that field entomologists need to consider, which is that sometimes their estimate of population density may be the mode and not the mean. If the distribution of insect 
abundance about the mode is skewed left or right, the management decision they make should also be based upon evidence about skewness. Currently, most entomological decisions do not use information on skewness in the decision making process.

Another ecological property relevant to MLIS is the fact that as the mean number of insects per sample unit (of any size) increases, the proportion of sample units occupied increases until all units are infested (Wilson and Room, 1983; Wilson et al., 1989; Wilson, 1993; Willers et al., 1990a). In practice, this property implies that the distance between infested plants decreases as the number of plants infested with at least one insect increases (Willers et al., 1999). A biological reality of the association between distance and density is that the percentage of plants infested more than once increases as insect density increases. At some point, the population is so far above an economic threshold that the issue of obtaining an estimate, based on the assumption of only one individual per plant, becomes moot. The MLIS design readily shows high population densities (Fig. 2) when insects frequently occur among adjacent rows along the transect line. In fact, we are learning that if the first two (or three) rows along the transect are occupied, and sampling occurs in favorable habitats delineated by imagery, then it is not necessary to continue the sampling of additional rows along that transect line. The scout should instead move to another region having spectral signatures that also denote states of crop development attractive to TPB, reducing further the time spent sampling at any particular location.

Benefits of the MLIS design are demonstrated for the larger sized sample units, primarily due to the influence of a dynamically increasing sample unit size. The use of the drop cloth to create these large sized sample units provides economy of sample effort (i.e., it is quick). With the better information that results from MLIS, it should be possible to develop spatially variable spray programs and/or devise improvements to management tactics employed against this cotton pest.

\section{Summary}

A more thorough temporal analysis of data of the kind used here are planned with field results from the 1998-2000 season. The enumerative algorithm represents a tool of tremendous potential in working with insect sampling data. Additional points of inquiry are raised by a suggestion to use the multinomial distribution and create sampling strata proportional to the actual areas of the crop having different spectral categories in a cotton field (R. Machavelli, pers com.). Using software for remotely sensed images (Schrader and Pouncy, 1997), the total area in a field in a particular category of spectral characteristics can be easily determined. Therefore, we could then easily investigate by enumeration a 'proportional to area' stratified sampling plan that simultaneously varies both sample size and sample unit size. An additional point of comparison would be the results of Christman (2000), who also compared various quadrat-based sampling schemes and population dispersion patterns.

\section{Acknowledgments}

The authors express appreciation to Mr. Kenneth Hood, Perthshire Farms, Gunnison, MS for support of the sampling research at the farm-scale. Thanks are due to the team at ITD Spectral Vision, 
Stennis Space Center, MS, for the acquisition of the multi-band imagery utilized in this study. Partial support provided by USDA-CSREES Special Grants 97-34374-3990 and 98-320112-675000.

\section{REFERENCES}

Beyer, W. H. (ed.) 1968. CRC Handbook of tables for probability and statistics, 2nd ed. CRC Press, Cleveland, $\mathrm{OH}$.

Christman, M. 2000. A review of quadrat-based sampling of rare, geographically clustered populations. J. Agric. Biol. Environ. Stat. 5: 168-201.

Copeland, J. and J. Haemer. 1999. Differences among women. SunExpert 10(2): 38-43.

Hayes, B. 1996. A question of numbers. Am. Sci. 84: 10-14.

Kaiser, L. 1983. Unbiased estimation in line-intercept sampling. Biometrics 39:965-976.

Kernighan, B. W. and D. M. Ritchie. 1988. The C programming language. Prentice Hall, Englewood Cliffs, NJ.

King, E. G., J. R. Phillips, and R. J. Coleman. (eds.). 1996. Cotton Insects and Mites: Characterization and Management. Vol. 3. The Cotton Foundation Reference Book Series. Cotton Foundation Publisher, Memphis, TN.

Lillesand, Thomas M. and R.W. Kiefer, 1987. Remote Sensing and Image Interpretation, 2nd edition. John Wiley and Sons, New York.

Lucas, H.A. and G.A.F. Seber. 1977. Estimating coverage and particle density using the lineintercept method. Biometrika 64:618-622.

Ludwig, J. A. and J. F. Reynolds. 1988. Statistical Ecology, A Primer on Methods and Computing. John Wiley and Sons, New York.

Manly, Bryan. F. J. 1997. Randomization, bootstrap and Monte Carlo methods in biology. 2nd edition. Chapman and Hall, London, UK.

McCloy, Keith R. 1995. Resource Management Information Systems, Process and Practice. Taylor and Francis.

McDonald, L. 1980. Line-intercept sampling for attributes other than coverage and density. J. Wildl. Manage. 44:530-533. 
McDonald, L. 1991. VIII. Line-intercept sampling for two-dimensional particles. p. viii.1-viii.9. In Sampling of biological populations and resource selection studies, Workshop Notes. Univ. of Wyoming, Laramie.

Pedigo, L. P. and G. D. Buntin (ed.) 1993. Handbook of sampling methods for arthropods in agriculture. CRC Press, Boca Raton, FL.

Pielou, E.C. 1977. Mathematical ecology. Wiley Inter-Science, New York.

Press, W. H., B. P. Flannery, S. A. Teukolsky, and W. T. Vetterling. 1989. Numerical Recipes. The Art of Scientific Computing (FORTRAN Version). Cambridge University Press, Cambridge.

Schrader, S. and R. Pouncy (ed.) 1997. ERDAS ${ }^{\circledR}$ Field Guide. 4th ed. ERDAS, Inc. Atlanta, GA.

Seal, M. 1999. Precision insecticide research shows potential input savings. Crop Decisions: October, pp. 14-15.

Sloane, N. J.A. and S. Plouffe. 1995. The encyclopedia of integer sequences. Academic Press, San Diego, CA.

Sloane, N.J.A. 1999. Sloane's on-line encyclopedia of integer sequences [Online]. Available at http://www.research.att.com/ njas/sequences/ (Verified 1 Apr. 2000).

Thompson, S. K. 1992. Sampling. Wiley-Interscience, New York.

Willers, J. L., D. L. Boykin, J. M. Hardin, T. L. Wagner, R. L. Olson, and M. R. Williams. 1990a. A simulation study on the relationship between the abundance and spatial distribution of insects and selected sampling schemes. p. 33-45. In G. Milliken and J. Schwenke (ed.) Proc. Appl. Stat. Agric., 2nd, Kansas State Univ., Manhattan, KS. 29 Apr.-1 May 1990.

Willers, J.L., R.L. Olson, M.R. Williams, and T.L. Wagner. 1990b. Developing a Bayesian approach for estimating the proportion of cotton plants at risk to insect attack. p. 246-247. In J. Brown and D. Richter (ed.) Proc. Beltwide Cotton Insect Control Conf., Las Vegas, NV. 9-14 Jan. 1990. Natl. Cotton Counc. Am., Memphis, TN.

Willers, J.L., S.R. Yatham, M.R. Williams, and D.C. Akins. 1992. Utilization of the line-intercept method to estimate the coverage, density, and average length of row skips in cotton and other row crops. p. 48-59. In G. Milliken and J. Schwenke (ed.) Proc. Appl. Stat. Agric., 4th, Kansas State Univ., Manhattan, KS. 26-28 Apr. 1992. 
Willers, J. L. 1998. Perspectives on sampling for Lygus in cotton: Applications of quadrat-based sampling schemes. p. 928-933. In P. Dugger and D. Richter (ed.) Proc. Beltwide Cotton Insect Control Conf., San Diego, CA. 5-9 Jan. 1998. Natl. Cotton Counc. Am., Memphis, TN.

Willers, J. L., M. R. Seal, and R. G. Luttrell. 1999. Remote sensing, line-intercept sampling for tarnished plant bugs (Heteroptera: Miridae) in Mid-south cotton [Online]. J. Cotton Sci. 3: 160-170. Available at http://www.jcotsci.org (verified 1 Jan. 2001).

Willers, J. L. and D. Akins. 2000. Sampling for Tarnished Plant Bugs in Cotton. Southwest. Entomol., Suppl. 23: 39-57

Williams, M.R., T.L. Wagner, and J.L. Willers. 1995. Revised protocol for scouting arthropod pests of cotton in the Midsouth. Miss. Agric. For. Exp. Stn. Tech. Bull. 206.

Williams, M. R. (ed.) 1998. Cotton Insect Losses-1997. p. 904-925. In P. Dugger and D. Richter (ed.) Proc. Beltwide Cotton Insect Control Conf., San Diego, CA. 5 - 9 Jan. 1998. Natl. Cotton Counc. Am., Memphis, TN.

Williams, Michael R. 2000. Cotton Insect Losses-1999. p. 884-913. In P. Dugger and D. Richter (ed.) Proc. Beltwide Cotton Insect Control Conf., San Antonio, TX. 4 - 8 Jan. 2000. Natl. Cotton Counc. Am., Memphis, TN.

Wilson, L. T. and P. M. Room. 1983. Clumping patterns of fruit and arthropods in cotton, with implications for binomial sampling. Environ. Entomol. 12: 50-54.

Wilson, L. T., W. L. Sterling, D. R. Rummel, and J. E. Devay. 1989. Quantitative Sampling Principles in Cotton IPM. p. 85-120. In R. E. Frisbie et al. (ed.) Integrated pest management systems and cotton production. Wiley \& Sons, New York.

Wilson, L. T. 1993. Estimating abundance, impact, and interactions among arthropods in cotton agroecosystems. p. 475-514. In L. P. Pedigo and G. D. Buntin (ed.) Handbook of sampling methods for arthropods in agriculture. CRC Press, Boca Raton, FL. 
Table 1. Description of the various sampling designs compared, where one is the original field observations (Willers et al., 1999) and the other four have been derived from the field design by exhaustive enumeration. The row $(r)$ and column $(c)$ size of the data matrix used to simulate each sample plan is listed in the last column (see eqn. 4).

\begin{tabular}{|c|c|c|c|c|c|}
\hline Sample Design & Imagery & No. Strata & $\underline{\text { Sample Size }}$ & Sample Unit Size & Matrix \\
\hline $\begin{array}{l}\text { Simple Random } \\
\text { (Traditional) }\end{array}$ & None & None & 4 & 6 row $f t$ & $24 \times 7$ \\
\hline $\begin{array}{l}\text { Stratified, Simple } \\
\text { Random }\end{array}$ & Yes & 4 & 4/stratum & 6 row $f t$ & $6 \times 7$ \\
\hline $\begin{array}{l}\text { Half MLIS, } \\
\text { Stratified }\end{array}$ & Yes & 4 & 4/stratum & 12 row $f t$ & $6 \times 2$ \\
\hline $\begin{array}{l}\text { MLIS, } \\
\text { Stratified }\end{array}$ & Yes & 4 & 4/stratum & 24 row $f t$ & $6 \times 1$ \\
\hline $\begin{array}{l}\text { Original MLIS, } \\
\text { Stratified }\end{array}$ & Yes & 4 & $6 /$ stratum & $\begin{array}{l}24 \text { row } f t \text { in } 8 \\
3 \text { row } f t \text { sub-units }\end{array}$ & $6 \times 8$ \\
\hline
\end{tabular}


Table 2. Frequency table of results after the exhaustive re-sampling of the MLIS transect data found in Willers et al. ((1999) see Table 1B therein). Each simulated plan (5 cases) assumes a simple random sampling design either unstratified (i.e., one case without imagery) or stratified (i.e., four cases where multiband, remotely sensed imagery spatially stratified the cotton crop into four habitat classes). The cotton insect pest is the Tarnished Plant Bug (Lygus lineolaris).

\section{Unstratified Best Habitat Good Habitat Fair Habitat Poor Habitat}

\begin{tabular}{|c|c|c|c|c|c|c|c|}
\hline Expected Total & $\underline{\text { Average }^{1}}$ & $\frac{\text { Mean No. }}{\text { per Acre }^{2}}$ & $\begin{array}{l}\text { Absolute } \\
\text { Frequency }^{3}\end{array}$ & $\begin{array}{l}\text { Absolute } \\
\text { Frequency }^{3}\end{array}$ & $\begin{array}{l}\text { Absolute } \\
\text { Frequency }^{3}\end{array}$ & $\begin{array}{l}\text { Absolute } \\
\text { Frequency }\end{array}$ & $\begin{array}{l}\text { Absolute } \\
\text { Frequency }^{3}\end{array}$ \\
\hline 0 & 0 & 0 & $5,275,184$ & 295 & 1884 & 21133 & 36015 \\
\hline 1 & 0.25 & 573 & $8,411,376$ & 2293 & 7618 & 12698 & 0 \\
\hline 2 & 0.5 & 1,146 & $6,645,409$ & 6568 & 11743 & 2100 & 0 \\
\hline 3 & 0.75 & 1,720 & $3,462,160$ & 9936 & 9306 & 84 & 0 \\
\hline 4 & 1.0 & 2,293 & $1,288,485$ & 9198 & 4199 & 0 & 0 \\
\hline 5 & 1.25 & 2,866 & 351,508 & 5370 & 1098 & 0 & 0 \\
\hline 6 & 1.5 & 3,439 & 68,864 & 1924 & 157 & 0 & 0 \\
\hline 7 & 1.75 & 4,012 & 9,243 & 392 & 10 & 0 & 0 \\
\hline 8 & 2.0 & 4,585 & 767 & 38 & 0 & 0 & 0 \\
\hline 9 & 2.25 & 5,159 & 30 & 1 & 0 & 0 & 0 \\
\hline & & Tota & $25,513,026$ & 36,015 & 36,015 & 36,015 & 36,015 \\
\hline
\end{tabular}

1 The average is the expected total $(\mathrm{E}(\mathrm{T}))$ divided by the sample size.

${ }^{2}$ The mean number per acre $=(E(T) / \text { Total no. row } f t)^{*} 13,756$ linear $f t$ per acre (see Williams et al., 1995).

${ }^{3}$ The sample unit size per sample for these five cases is 6 linear row $f t$ with a sample size of $n=4$. 
Figure 1. Histogram of the expected total of tarnished plant bugs collected from the Best habitat strata delineated by remote sensing. The sample unit simulated is twice (i.e., 12 row $f t$ ) the size of that used for the same habitat presented in Table 2. The sample size is fixed at $n=4$. The total number of unique outcomes were enumerated from the original field data (Willers et al., 1999; Table 1B) and numbers 5,760.

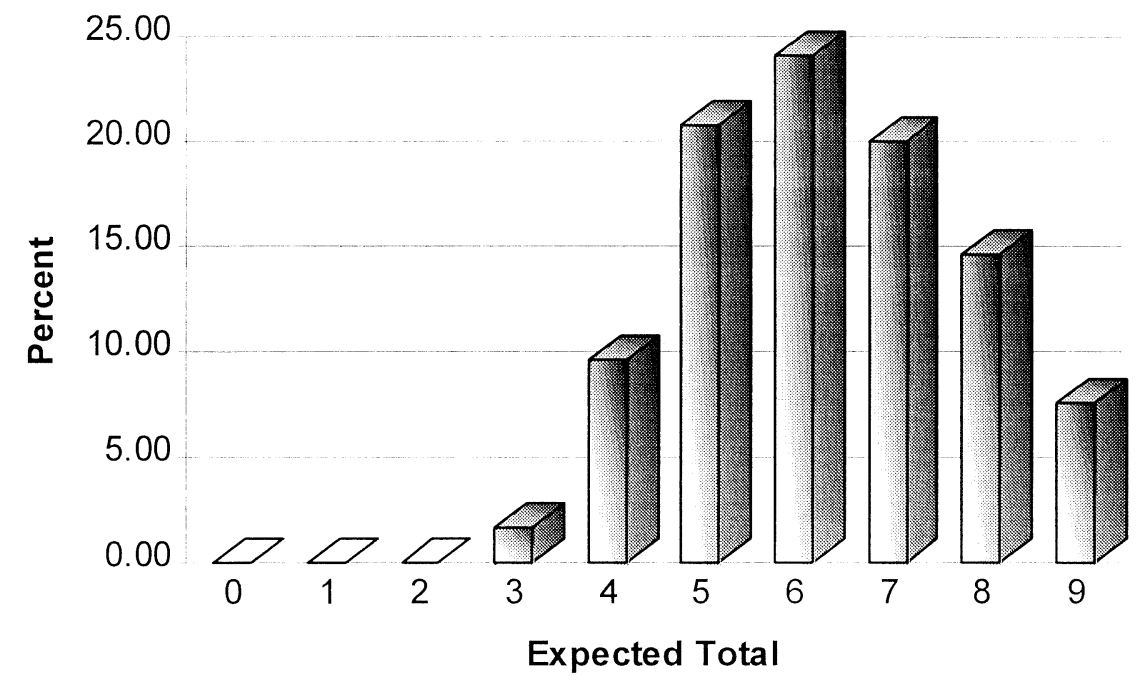


Figure. 2. Histogram of enumeration results for the Best habitat showing the expected sampling distribution for a sample of size $n=4$ using a sample unit size (i.e., 24 row $\mathrm{ft}$ ) identical to the original sample unit size. Only a total of 15 unique draws are possible from the original data set (Willers et al., 1999; Table 1B) where the sample size (i.e., $n=6$ ) was slightly larger than the simulated plan.

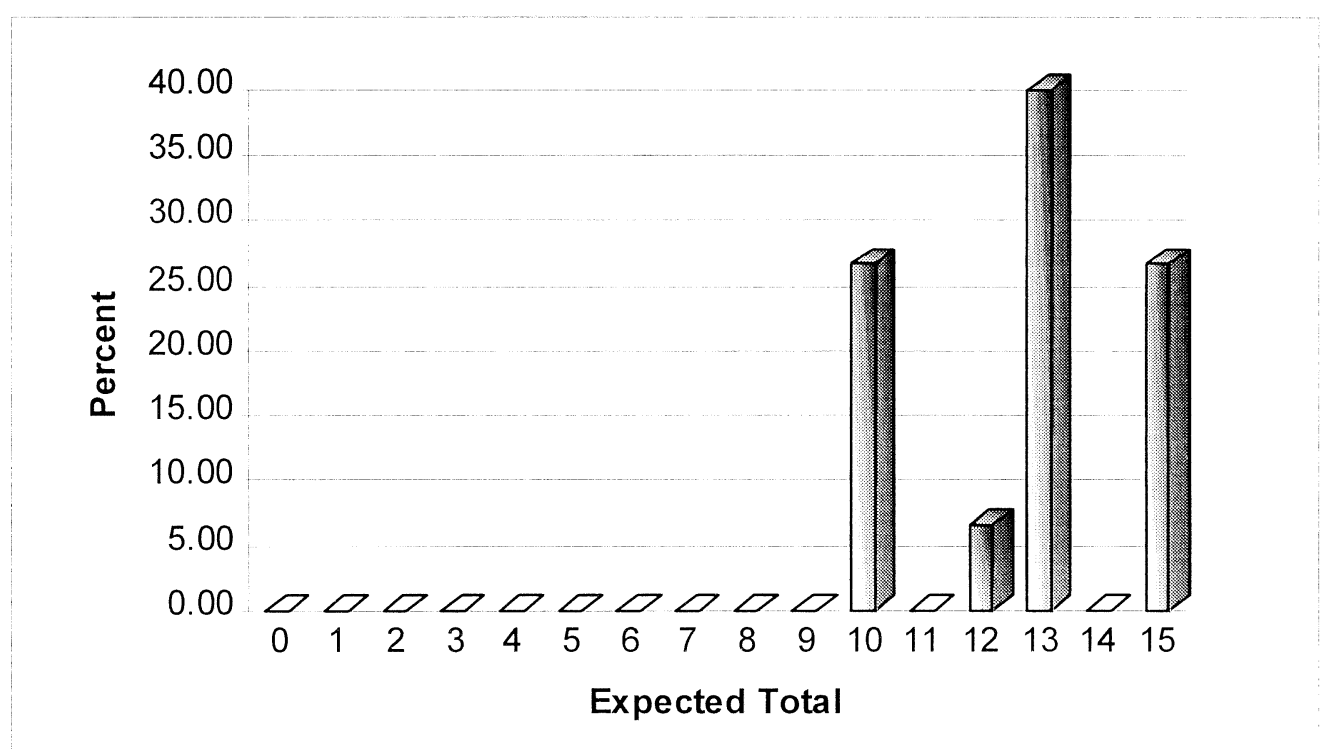

